\title{
Key regulator of cellular metabolism, estrogen- related receptor $\alpha$, a new therapeutic target in endocrine-related gynecological tumor
}

This article was published in the following Dove Press journal:

Cancer Management and Research

\author{
GuiFen Liu' \\ PengMing Sun ${ }^{1,2}$ \\ BinHua Dong' \\ Jalid Sehouli ${ }^{3}$ \\ 'Laboratory of Gynaecologic \\ Oncology, Fujian Provincial Maternity \\ and Children's Hospital, Affiliated \\ Hospital of Fujian Medical University, \\ 35000 I Fuzhou, Fujian, People's \\ Republic of China; ${ }^{2}$ Department \\ of Gynaecology, Fujian Provincial \\ Maternity and Children's Hospital, \\ Affiliated Hospital of Fujian \\ Medical University, 35000I Fuzhou, \\ Fujian, People's Republic of China; \\ ${ }^{3}$ Department of Gynaecologic \\ Oncology and Gynaecology, Charitél \\ Campus Virchow-Klinikum, European \\ Competence Centre for Ovarian \\ Cancer University of Berlin, Berlin \\ 13353, Germany
}

\begin{abstract}
The estrogen-related receptor $\alpha(\operatorname{ERR} \alpha)$, is an orphan transcription factor. Recently, many studies have reported its regulatory mechanisms and transcriptional targets after identification. Therefore, it may be eligible to join the rank of other nuclear receptors that control almost all aspects of cell metabolism. Cellular metabolism reprogramming plays a key role in fueling malignant change. The purpose of this review was to demonstrate that the ERR $\alpha$ plays an important role in the association between gynecological endocrine-related tumors and energy metabolism. Furthermore, regulation of ERR $\alpha$ may represent a promising strategy to induce cellular metabolic vulnerability of cancer from different origins. Thus, a comprehensive understanding of current treatment strategies may be achieved.
\end{abstract}

Keywords: orphan receptor, ovarian malignancy, breast malignancy, endometrial malignancy

\section{Introduction}

Recently, with the development of physiological and biochemical research, a new nuclear orphan receptor (OR) has been the focus of increasing interest and was named an OR because of its unique physiological effect and the inability to identify corresponding specific natural ligands. Moreover, it has characteristics of non-ligand-dependent activation and transcription and interacts with numerous factors and targeted genes through a DNA-binding domain. Giguère et $\mathrm{l}^{1}$ first reported a family of ORs called estrogen-related receptors (ERRs), which included ERR $\alpha$, ERR $\beta$, and ERR $\gamma$. Among them, the ERR $\alpha$ subtype, which has attracted the greatest attention to date (Figure 1), regulates various cellular events, such as energy metabolism and mitochondrial biogenesis where it acts in coordination with its specific transcriptional coactivators, including coactivator-1 $\alpha$ (PGC-1 $\alpha)$, PGC-1 $\beta$, peroxisome-proliferator activated receptor $\gamma(\operatorname{PPAR} \gamma),{ }^{2}$ steroid receptor coactivators, and corepressor nuclear receptor interacting protein 140 (RIP140). ${ }^{3}$ ERR $\alpha$ is considered to control energy homeostasis, ${ }^{4}$ by regulating lipid handling, gluconeogenesis, glycolysis, and mitochondrial respiration. Furthermore, metabolic reprogramming is thought to be a characteristic of cancer. ${ }^{5-10}$ Under stress conditions, it can provide tumor cells with an adaptable metabolism and survival mechanisms. ${ }^{11-13}$ Recent studies have reported that the different expression levels of ERR $\alpha$ have important clinical significance in breast, ${ }^{14}$ prostate,${ }^{15}$ and colon ${ }^{16}$ cancers. Therefore, the ERR $\alpha$ was presumed to be an independent factor for the poor prognosis of hormone-related tumors. ${ }^{17}$ Inspired by the successful application of ERs in breast cancer and the discovery that ERR $\alpha$ is involved in regulating
Correspondence: PengMing Sun Laboratory of Gynaecologic Oncology, Fujian Provincial Maternity and Children's Hospital, Affiliated Hospital of Fujian Medical University, No 18. Dao Shan Road, 35000I Fuzhou, Fujian, People's Republic of China

Tel +8659187558732

Fax+86 59I 87551247

Email sunfemy@hotmail.com 


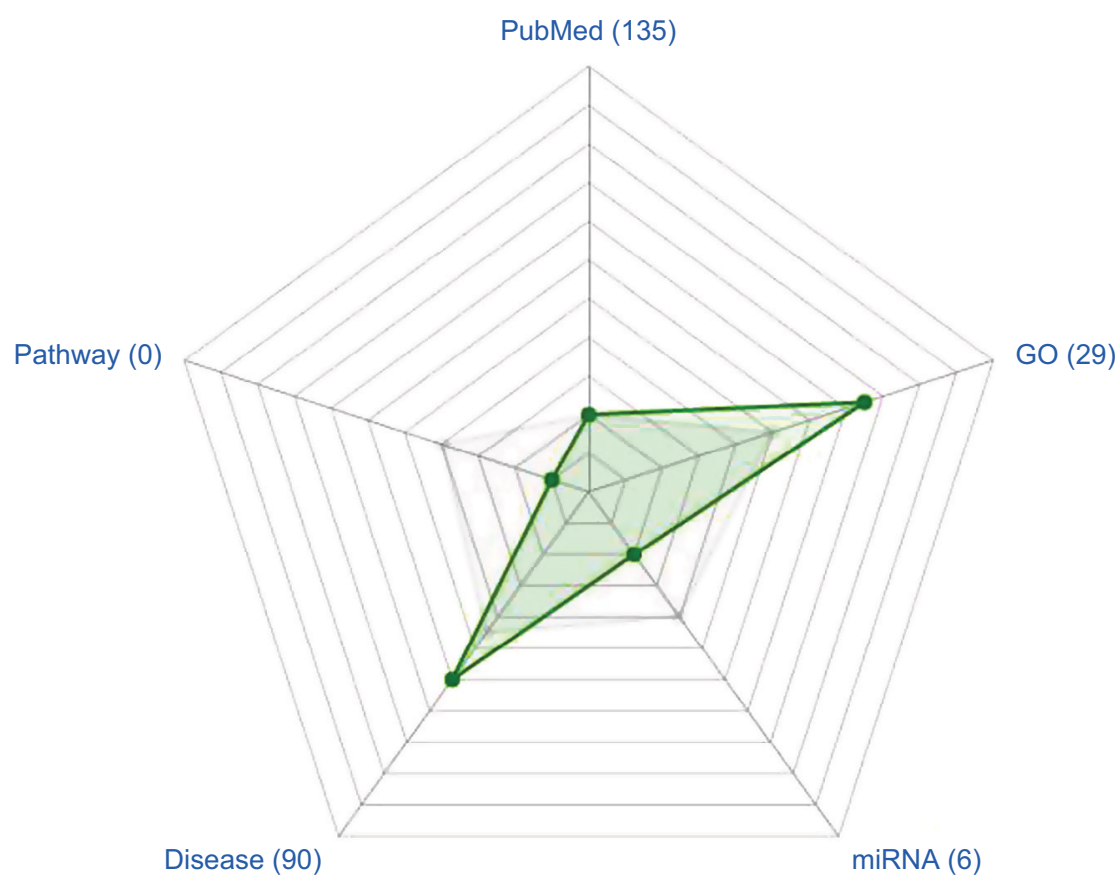

Figure I ERR $\alpha$, a hot topic.

Notes: PubMed, total number of times reported in the literature. GO, number of biological processes participating in the Gene Ontology database. miRNA, number of documented miRNAs. Disease, number of diseases associated with the published literature. Pathway, signals participating in Kyoto Encyclopedia of Genes and Genomes (KEGG) database. Gray spot (median), position at the level of the number of pathways in which genes participate in the signal. Green spot, the relative position of the number of ERR $\alpha$ participants at the signal pathway level.

Abbreviation: $E R R \alpha$, estrogen-related receptor $\alpha$.

cellular energy metabolism by controlling targeted genes, increasing interests have been expressed in investigating how this metabolic regulator affects the occurrence and development of carcinoma and in developing clinically useful ERR $\alpha$ antagonists. Furthermore, emerging information on the ERR $\alpha$ has highlighted molecules of its upstream and downstream pathways, which may be inhibited to achieve therapeutic synergism with ERR $\alpha$ antagonists.

\section{$E R R \alpha$, a master regulator of cellular metabolism in different tissues}

Localization analysis in different metabolic tissues such as mouse heart, ${ }^{18}$ macrophages,${ }^{19}$ kidney, ${ }^{20}$ liver, ${ }^{21}$ and human cancer cells ${ }^{22}$ have identified numerous genes. These findings might suggest that the ERR $\alpha$ acts as a major regulator of energy metabolism. From the metabolic gene network, there are numerous mitochondrial genes involved in mitochondrial function, such as energy production, amino acid metabolism, nucleotide biosynthesis, etc. ERR $\alpha$ occupies the extended promoter region of genes encoding numerous enzymes involved in such processes as carbohydrate and pyruvic acid metabolism and the tricarboxylic acid cycle (TCA). ${ }^{23,24}$

Furthermore, the ERR $\alpha$ regulon includes all genes encoding enzymes involved in the glycolysis pathway to integrate two main energy-generating pathways under the control of some identical transcription factors (TFs) as well as the promoter regions of genes contributing to lipid metabolism (including acyl-CoA dehydrogenase medium chain $[A C A D M]$, fatty acid synthase $[F A S N], 2$,4-dienoylCoA reductase 1 [DECR1], carnitine palmitoyltransferase 1A [CPT1A], hydroxyacyl-coenzyme A dehydrogenase/3ketoacyl-coenzyme A thiolase/enoyl-coenzyme A hydratase (trifunctional protein), alpha subunit [HADHA], ferrochelatase $[F E C H]$, AMP-activated protein kinase $[A M P K]$ signaling [including acetyl-CoA carboxylase 2 [ACC2], ATP-AMP transphosphorylase 2 [AK2], and carnitine palmitoyltransferase 2 [CPT2]), suggesting that $\mathrm{ERR} \alpha$ is involved in a wide range of functions in metabolism.

Studies have shown that ERR $\alpha$ controls multiple mitochondrial functions including fatty acid beta-oxidation (FAO, eg, malonyl coenzyme A decarboxylase $[M C D]$ ), the TCA cycle (eg, succinate dehydrogenase complex subunit D integral membrane protein $[S D H D]$ ), oxidative phosphorylation (OXPHOS, eg, cytochrome c, somatic [CYCS] and NADH:ubiquinone oxidoreductase core subunit $\mathrm{S} 1$ [NDFUS1]), ATP production (eg, ATP5B and ATP5G3), and export (eg, solute carrier family 25 member 4 [SLC25A4]). In addition, it is involved in controlling the transcription of mitochondrial genome-encoded genes (eg, transcription factor B2, mitochondrial (TFB2M)) and translation apparatus (eg, mitochondrial ribosomal protein L19 [MRPL19]). ${ }^{4}$ 


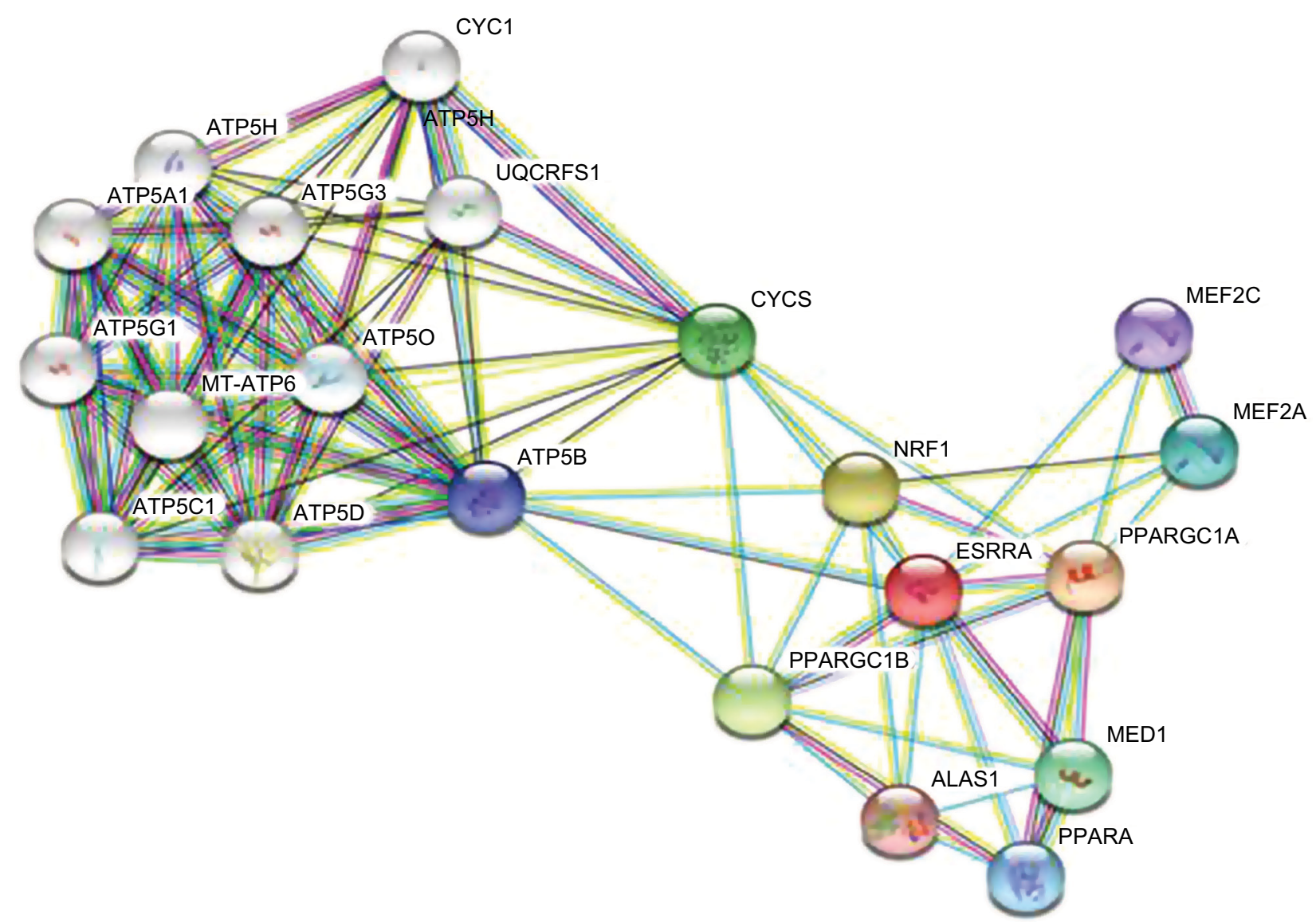

Figure 2 Genes related to ERR $\alpha$ obtained from STRING database analysis.

Notes: Each node represents different proteins: among them, $\odot$ is the target protein of ERR $\alpha$. Edges: $\ominus-\ominus$, from the curated database; $\ominus-\ominus$, experimentally determined; the remaining colors are all predicted interactions.

Abbreviation: ERR $\alpha$, estrogen-related receptor $\alpha$.

Twenty types of metabolism-related genes regulated by ERR $\alpha$ were identified using bioinformatics analysis with the STRING 10.5 database of protein-protein interactions. ${ }^{25}$ The data showed that PGC- $1 \alpha$ and peroxisomeproliferator activated receptor $\alpha$ (PPAR $\alpha)$ were clearly related to ERR $\alpha$ (Figure 2). ERR $\alpha$ as a master metabolism regulator was well known to have an important role in maintaining cancer phenotypes by altering cellular bioenergetics ${ }^{26,27}$ Investigating an estrogen signaling-independent function for the ERR $\alpha$ in tumor is arousing increasing interest. In conclusion, the PGC- $1 \alpha / E R R \alpha$ axis, as the key point of energy metabolism in malignant tumor cells, is involved in mediating the metabolism through transcription factors. Figure 3 shows the signal pathways and molecular mechanisms of how ERR $\alpha$ affects the bioenergetics of cancer cells, and then changes the behavior of invasion, metastasis and drug resistance of cancer cells based on the bioinformatics analysis.

\section{Through mediating metabolic adaptations, $E R R \alpha$ drives cancer cell growth, division, and proliferation}

Metabolic alterations support tumor progression, including rapid growth, proliferation, drug resistance, migration, and metastasis. The metabolic alterations include variations in levels of fatty acid oxidation (FAO) and lipid biosynthesis, increased glutamine uptake and glutaminolysis, elevated flux through the pentose phosphate pathway and aerobic glycolysis, oxidative phosphorylation. ${ }^{28}$ The ERR $\alpha$ has been involved in the processes mentioned above through the transcriptional regulation of associated target genes. ${ }^{24}$ Recently, many researchers have confirmed the important function of ERR $\alpha$ as well as its corresponding cofactors (in particular, PGC-1s) in the metabolic profiles of tumor cells. ${ }^{29}$ Based on the metabolic functions mediated by ERR $\alpha$, the specific pathway mediating endocrine-related gynecological cancer has been of interest and is still unclear. 


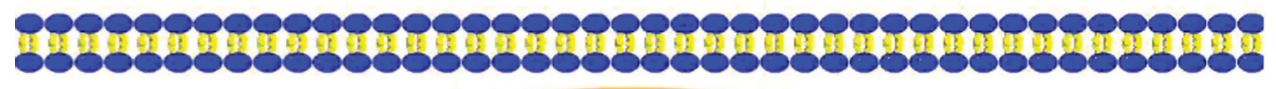

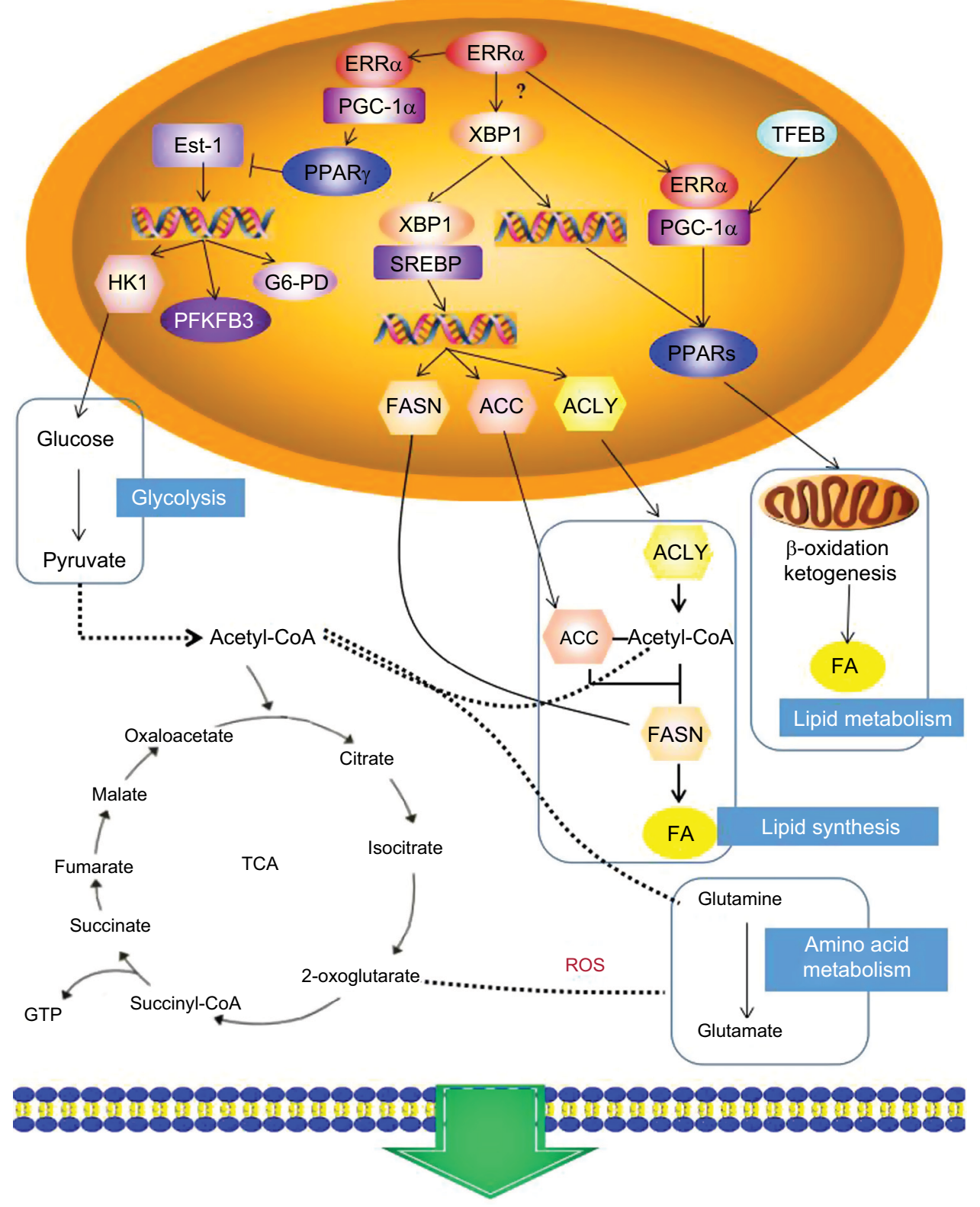

Proliferation, Invasion, metastasis, apoptosis, drug resistance

Figure 3 The potential mechanism of ERR $\alpha$ in energy metabolism: the PGC-I $\alpha / E R R \alpha$ axis, as the key point of energy metabolism in cancer cells, is involved in mediating the metabolism of lipids, glycolysis, and glutamine through transcription factors that affect the bioenergetics of cancer cells, and then changes the behavior of invasion, metastasis and drug resistance of cancer cells.

Abbreviations: ERR $\alpha$, estrogen-related receptor $\alpha$; PPAR $\gamma$, peroxisome-proliferator activated receptor $\gamma$; FASN, fatty acid synthase; TCA, tricarboxylic acid cycle; ROS, reactive oxygen species.

The biological characteristics of cancer cells include unrestrained cell growth and division. A recent study reported that during glucose deprivation, some breast cancer cells switched to metabolism of lactic acid to provide the essential energy and metabolites for prolonged periods. The switch from glucose to lactate enhances resistance to inhibitors of phosphoinositide 3-kinase (PI3K)/mechanistic target of rapamycin kinase (mTOR) signaling, which is necessary for cancer cell rapid growth and cellular survival. Moreover, ERR $\alpha$ was shown to be crucial for OXPHOS, and the expression of gene-coding enzymes linked to lactate metabolism, such as monocarboxylate transporter 1 (MCT1) and lactate dehydrogenase B (LDHB). Furthermore, inhibition of ERR $\alpha$ by antagonists abrogated lactate metabolism and cellular growth. ${ }^{30}$

The division in normal cells is tightly regulated by a series of events. The progress depends mainly on both the cell 
cycle and large amounts of energy. ${ }^{27}$ The transition to fueling anabolic processes must happen to produce sufficient nucleic acids, lipids and proteins for these events. ${ }^{27}$ The expression P21 blocked the G1/S transition after inhibiting ERR $\alpha$ in breast cancer. ${ }^{31}$ This ERR $\alpha$-dependent arrest at the G1/S checkpoint was mirrored. ${ }^{32}$ In view of the fact that tumor cells will increase the glycolytic pathway in $\mathrm{G} 1$ phase, ${ }^{33,34}$ it may be concluded that ERR $\alpha$ can regulate transition through the cell cycle by controlling cellular energetics. Therefore, Willy et $\mathrm{al}^{35}$ and Chisamore et $\mathrm{al}^{36}$ used two synthetic inverse agonists to deactivate ERR $\alpha$ to further study the effects of expression of ERR $\alpha$ on the cell cycle. The results of these two studies revealed that exposure to the two synthetic inverse agonists blocked the growth of breast tumor cell lines and inhibited their tumorigenicity in vivo. The effect of the synthetic inverse agonist, compound XCT790, was accompanied by cell cycle arrest in the G1/S transition as well as production of p21 and hypophosphorylation of retinoblastoma $(\mathrm{Rb}) .^{31}$ Interestingly, in uterine endometrial carcinoma, knockdown of ERR $\alpha$ caused cell cycle blockade at the G2/M phase through cell cycle analysis, whereas it induced cell cycle arrest in the mitotic phase in time-course experiments. ${ }^{37}$ Thus, we can conclude that ERR $\alpha$ knockdown caused cell cycle blockade at different phases by energy transition.

\section{The metabolic effects of ERR $\alpha$ promote cancer migration and metastasis}

A feature of invasive cancers is that their ability to metastasize, which is determined by their invasiveness and migratory ability, as well as tumor angiogenesis that not only provides sufficient oxygen and nutrients but is also a pathway for cells to remove waste. ${ }^{38}$ The underlying mechanisms of these effects have not yet been elucidated, but may involve ERR $\alpha$-driven genes to regulate tumor cell expansion. ERR $\alpha$ synergizes with and increases the transcriptional activities of hypoxia-inducible factor (HIF), ${ }^{39}$ which controls glycolytic metabolism ${ }^{40}$ and has been associated with the HIF $\alpha / \beta$ heterodimer in promoting its transcriptional activity on angiogenic and migratory target genes such as VEGF. ${ }^{41,42}$ Further, Semenza ${ }^{43}$ has confirmed that ERR $\alpha$ directly interacted with HIF-1 $\alpha$, which controls the transcription involved in angiogenesis and reprogramming energy metabolism, thereby enhancing HIF-1 signaling. ${ }^{43} \mathrm{HIF}-1 \alpha$ expression and the PI3K/Akt/STAT3 (acute phase response factor) signaling pathways are known as key pathways in regulating the expression of VEGF. Thus, we can conclude that VEGF and $\mathrm{PI} 3 \mathrm{~K} / \mathrm{Akt} / \mathrm{STAT} 3$ signaling pathways are involved in the
ERR $\alpha$ block-mediated anti-angiogenesis in breast tumor cells. ${ }^{44}$ Furthermore, ERR $\alpha$ increased the expression of endothelial nitric oxide synthase, to promote angiogenesis. ${ }^{45-47}$ Altogether, ERR $\alpha$-regulated positive expression of VEGF, which has been reported in breast and cervical tumor, however, pharmacological inhibition of ERR $\alpha$ activity decreased tumor growth and angiogenesis. ${ }^{39,48,49}$

The propensity of epithelial cancer cells to localize to metastatic sites is primarily dependent on epithelialmesenchymal transition (EMT) in combination with the accumulation of migratory and invasive capacities. Wang et $\mathrm{al}^{50}$ found that ERR $\alpha$ expression and EMT in ovarian cancer cell lines were inhibited by cordycepin, which downregulated mitochondrial activity, avoiding EMT and migration in vitro. Inhibition of ERR $\alpha$ decreases the metastatic ability by interfering with epithelial-to-mesenchymal gene program suppression. Interestingly, the metabolic enzymes and metabolic profiles are statistically different between proliferating cells and migrating cells undergoing EMT, which exhibit alterations. ${ }^{51}$ On the other hand, depletion of fatty acid synthase (FASN) and succinate dehydrogenase induced EMT in ovarian cancer cells, ${ }^{52}$ which implied that metabolic alterations have an important role in regulating EMT. In addition, the ERR $\alpha$ can mediate Snail, which is a crucial regulator of EMT. ${ }^{53}$ Furthermore, Zhao ${ }^{54}$ and Dwyer ${ }^{55}$ reported that crosstalk with the $\mathrm{Wnt} / \beta$-catenin signaling pathway promotes ERR $\alpha$-mediated cell migration to regulation of WNT11. Inhibiting the expression of ERR $\alpha$ decreases the migratory capacity of cancer cells, as well as ablation of $\beta$-catenin, so the ERR $\alpha / \beta$-catenin/WNT11 signaling pathway may be biologically significant. Moreover, postgenomics has identified target genes of ERR $\alpha$, which promoted angiogenesis and were closely related to cellular invasion and migration, such as fibroblast Growth Factor 2 (FGF2) and C-X-C chemokine receptor type 4 (CXCR4). ${ }^{56}$

On the other hand, FAO is very important for energy production of cancer cells under some conditions. ${ }^{57}$ The transfer of lipids from the microenvironment triggers FAO, which in turn promotes metastasis. ${ }^{58}$ In fact, it has been reported that $\beta$-oxidation of fatty acids, protein levels of ERR $\alpha$, and glucose metabolism levels of tumor cells in the brain increases metastases. Metabolic reprogramming driven by ERR $\alpha$ contributes to the variation of these observed metastatic potentials. Cancer cells exhibit different metabolic characteristics at different tumor metastasis sites. Thus, along with the use of energy-producing pathways in cancer cells is altered to promote colonization and survival in specific organs. 
ERR $\alpha$ mediates metabolic transformation, driving drug resistance in tumor cells

Experiments in vivo have shown that the oxygenation and nutritional status of the tumor were dynamic. In addition, tumor cells can rapidly ingest and metabolize extremely low levels of glucose, but cancer cells must depend on other sources to gain energy in some conditions. For example, some breast carcinoma cells can use lactic acid as their primary source of energy, allowing them to survive without glucose for long periods. Studies have shown that ERR $\alpha$ regulates the expression of genes required for lactic acid utilization, and it has been shown in isotope analysis experiments that inhibition of ERR $\alpha$ activity inhibits lactate oxidation. ${ }^{59}$ In the absence of glucose, lactate oxidative capacity is essential for breast cancer cells, and ERR $\alpha$ antagonists can disrupt mitochondrial function, thereby inhibiting cellular utilization of lactic acid. It has further been demonstrated that most breast cancer cells actively involved in OXPHOS are not sensitive to the inhibition of PI3K/mTOR inhibitors, but the efficacy of these targeted therapies can be enhanced by the combination of ERR $\alpha$ antagonists. ${ }^{30}$

ERR $\alpha$, a major regulator of energy metabolism, was restored in lapatinib-resistant breast tumor cells via the mTOR signaling pathway. Under therapeutic stress circumstance, ERR $\alpha$ reexpression in drug-resistant cells can trigger changes in cellular metabolism, such as increasing in glutamine metabolism and detoxification of reactive oxygen species required for cell survival. ERR $\alpha$ inverse agonist blocked these metabolic changes and relieved lapatinib resistance in a HER2-induced mouse model of breast cancer. This study reveals the molecular mechanism by which ERR $\alpha$-mediated metabolic reprogramming promotes the survival of lapatinibresistant cancer cells and demonstrates the potential of inhibiting ERR $\alpha$ as an effective adjuvant therapy for HER2positive but poor outcome breast carcinoma. ${ }^{60}$

\section{ERR $\alpha$ plays an important function in endocrine-related gynecological carcinoma}

Hormones are a very important factor in maintaining the physiological functions of women, and their imbalance is closely associated with the initiation and development of malignant carcinomas. The three most common malignancies in females are breast cancer, endometrial carcinoma (EC), and ovarian carcinoma (OC), which are related to hormonal dysfunction, especially estrogen dysfunction. ${ }^{61}$ In the last few years, the incidence of these malignant diseases has increased and is still not restrained sufficiently. The study of the regulation of physiological function or effects of hormones, especially in endocrine therapy that requires super selective intervention hormone receptor subtypes as the main means of hormone-dependent/related tumor, has become a new research hotspot in translational medicine. ${ }^{62-64}$

Using selective estrogen receptor (ER) antagonist (selective ER modulators, SERMs) targeting the ER in treating tumors in patients has produced varying clinical effects. For instance, ideal biotherapeutic effects can be achieved in breast cancer, whereas these agents have both anticancer and carcinogenic effects in endometrial carcinoma. Furthermore, the effect of endocrine therapy in ovarian cancer is unclear. ${ }^{65,66}$ Obviously, these phenomena cannot be reasonably explained by the classical estrogen-ER signaling pathway theory.

Because of the known structural homology between ERR $\alpha$ and $E R \alpha$ as well as the crucial role of ER $\alpha$ in breast tumors, studies have mainly concentrated on the latent association with the traditional ER $\alpha$ in the early years. Initially, it was a surprising finding that ERR $\alpha$ binds DNA segments harboring the estrogen-response element (ERE) in vitro. ${ }^{67-69}$ After that, in different endocrine-related cancers, the potential of ERR $\alpha$ as a biomarker has been gradually proved. ${ }^{2}$ Compared to the expression in normal tissues, ERR $\alpha$ expression was elevated in tumor samples from patients with ovarian cancer. ${ }^{16}$

In ovarian, endometrial and colorectal cancers, ERR $\alpha$ expression increases with advancing clinical stages, so we concluded there is a strong positive correlation between ERR $\alpha$ and tumor aggressiveness. ${ }^{16,70,71}$ In breast cancer, ERR $\alpha$ expression has also been associated with unfavorable clinical outcomes. ${ }^{72}$ Further, in an animal model of brain metastasis, it was observed that the mRNA expression of ERR $\alpha$ increased. ${ }^{73}$ Our previous study showed that ERR $\alpha$ was correlated with the development of ovarian cancer, which could be used as a marker for poor prognosis and it may be associated with decreased patient survival. ${ }^{17}$ Similar observations have also been made in endometrial tumors.

With the continuous exploration of tumor development mechanisms, in 2011, American scientists Douglas Hanahan and Robert A Weinberg ${ }^{74}$ identified six additional characteristics of tumor cells increasing the existing number to 10: self-sufficiency in growth signals, resistance to cell death, unlimited replicative ability, insensitivity to growth inhibitory signals, sustained angiogenesis, evasion of immune surveillance, tissue invasion and transfer, promotion of tumor inflammation, genomic instability and mutation, and abnormal cell energy. The characteristics of tumor cells are unlimited growth and division, which requires considerable 
energy, especially for producing enough nucleic acids, lipid, and protein for each cell, which must undergo accelerated metabolism and biosynthesis. ${ }^{27}$

The changes of cellular metabolism in cancer cells include enhanced glycolysis and oxidation phosphorylation, glutamine uptake, increased glutamine levels, FAO and lipid biosynthesis level changes, and increased pentose phosphate metabolism. Thus, the establishment of ERR $\alpha$ as a master regulator of cellular metabolism has generated renewed interest in investigating the coordination of ERR $\alpha$-driven metabolism in endocrine-related gynecological cancers.

\section{Advances in $\mathrm{ERR} \alpha$ antagonist development}

Considering the role of ERR $\alpha$ in cell metabolism, many researchers have attempted to identify molecules with agonist activity for the treatment of metabolic diseases such as breast cancer and diabetes. However, compounds with significant ERR $\alpha$ agonist activity have not been identified in recent years. Some antagonist/inverse agonists have been found to inhibit ERR $\alpha$ activity in vitro or in vivo. Although these compounds have not been used clinically, they play a key role in exploring the biological role of $E R R \alpha$ and the pathways involved. The first selective ERR $\alpha$ antagonist, XCT790, can bind ERR $\alpha$ and blocking its interaction with coactivators, downregulating the expression of target genes for ERR , and inhibiting cell proliferation in vitro. ${ }^{35,75,76}$

Compound A ([N-[(2Z)-3-(4, 5-dihydro-1, 3-thiazol2-yl)-1, 3-thiazolidin-2-ylidene]-5Hdibenzo[a,d][7]annulen5-amine], an ERR $\alpha$ selective antagonist, exhibits growth inhibition of ER-positive and ER-negative breast tumor both in vitro and in vivo. ${ }^{36} \mathrm{~A}$ diaryl ether-based thiazolidinedione (compound 29) for the treatment of metabolic disease, ${ }^{77}$ as well as a selective ERR $\alpha$ antagonist, has good pharmacokinetic properties, but is only effective in animal models of insulin resistance and obesity, its role in breast cancer has not been confirmed.

Zhang et al reported that HSP1604 (methyl-N-(4-(((4butoxy-N-(4-((N-(4-methylbenzyl), methylsulfonamido) methyl)phenyl)phenyl)sulfonamido)methyl)phenyl)-N(methylsulfonyl)glycinate) was the strongest inhibitor of the constitutive transcriptional activity of ERR $\alpha$. It directly binds to the ERR $\alpha$ to decrease its expression and downstream target genes. In vitro, HSP1604 also inhibited the proliferation of multiple cancer cells lines and the migration of breast cancer cells. ${ }^{78}$ These compounds are extremely valuable for the discovery of new drugs, making ERR $\alpha$ an alternative strategy for treating endocrine-related gynecological tumors and other related diseases.

\section{Conclusion and perspectives}

The findings summarized in this review support the key function of ERR $\alpha$ in coordinating metabolic programs, which subsequently promote tumor cell growth, division, proliferation, angiogenesis, migration, metastasis, and drug resistance. Although the effectiveness of some ERR $\alpha$ antagonists have been validated in animal studies, they have not been reported in clinical trials. However, as a major regulator of the energy metabolism process, changes in the activity of ERR $\alpha$ would be a valuable strategy for the development of therapies targeting cancer metabolism. Recent research studies show the causal role of ERR $\alpha$ in cancer pathogenesis. With the enhanced understanding of the receptor as a drug target, it is believed that the information highlighted in this review will encourage the development of new therapeutic strategies that are urgently needed to treat endocrine-related gynecologic cancers.

\section{Acknowledgments}

The authors thank Miss Lili Chen and Miss Meimei Huang for their excellent assistance in this work. This study was supported by grants 2017J01233, 2016J01428, and 2017Y9062 from the Natural Science Foundation of Fujian.

\section{Disclosure}

The authors report no conflicts of interest in this work

\section{References}

1. Giguère V, Yang N, Segui P, Evans RM. Identification of a new class of steroid hormone receptors. Nature. 1988;331(6151):91-94.

2. Deblois G, St-Pierre J, Giguère V. The PGC-1/ERR signaling axis in cancer. Oncogene. 2013;32(30):3483-3490.

3. Nichol D, Christian M, Steel JH, White R, Parker MG. RIP140 expression is stimulated by estrogen-related receptor alpha during adipogenesis. J Biol Chem. 2006;281(43):32140-32147.

4. Giguère V. Transcriptional control of energy homeostasis by the estrogen-related receptors. Endocr Rev. 2008;29(6):677-696.

5. Boroughs LK, Deberardinis RJ. Metabolic pathways promoting cancer cell survival and growth. Nat Cell Biol. 2015;17(4):351-359.

6. Ward PS, Thompson CB. Metabolic reprogramming: a cancer hallmark even Warburg did not anticipate. Cancer Cell. 2012;21(3):297-308.

7. Hensley CT, Wasti AT, Deberardinis RJ. Glutamine and cancer: cell biology, physiology, and clinical opportunities. J Clin Invest. 2013;123(9):3678-3684.

8. Currie E, Schulze A, Zechner R, Walther TC, Farese RV. Cellular fatty acid metabolism and cancer. Cell Metab. 2013;18(2):153-161.

9. Locasale JW, Serine LJW. Serine, glycine and one-carbon units: cancer metabolism in full circle. Nat Rev Cancer. 2013;13(8):572-583.

10. Weinberg SE, Chandel NS. Targeting mitochondria metabolism for cancer therapy. Nat Chem Biol. 2015;11(1):9-15. 
11. Seyfried TN, Flores RE, Poff AM, D'Agostino DP. Cancer as a metabolic disease: implications for novel therapeutics. Carcinogenesis. 2014;35(3):515-527.

12. Bobrovnikova-Marjon E, Hurov JB. Targeting metabolic changes in cancer: novel therapeutic approaches. Аnпи Rev Med. 2014;65:157-170.

13. Stäubert C, Bhuiyan H, Lindahl A, et al. Rewired metabolism in drugresistant leukemia cells: a metabolic switch hallmarked by reduced dependence on exogenous glutamine. J Biol Chem. 2015;290(13): 8348-8359.

14. Suzuki Y, Wakita D, Chamoto K, et al. Liposome-encapsulated CpG oligodeoxynucleotides as a potent adjuvant for inducing type 1 innate immunity. Cancer Res. 2004;64(23):8754-8760.

15. Cheung CP, Yu S, Wong KB, et al. Expression and functional study of estrogen receptor-related receptors in human prostatic cells and tissues. J Clin Endocrinol Metab. 2005;90(3):1830-1844.

16. Cavallini A, Notarnicola M, Giannini R, et al. Oestrogen receptor-related receptor alpha (ERRalpha) and oestrogen receptors (ERalpha and ERbeta) exhibit different gene expression in human colorectal tumour progression. Eur J Cancer. 2005;41(10):1487-1494.

17. Sun P, Sehouli J, Denkert C, et al. Expression of estrogen receptorrelated receptors, a subfamily of orphan nuclear receptors, as new tumor biomarkers in ovarian cancer cells. J Mol Med. 2005;83(6):457-467.

18. Dufour CR, Wilson BJ, Huss JM, et al. Genome-wide orchestration of cardiac functions by the orphan nuclear receptors ERRalpha and gamma. Cell Metab. 2007;5(5):345-356.

19. Sonoda J, Laganière J, Mehl IR, et al. Nuclear receptor ERR alpha and coactivator PGC-1 beta are effectors of IFN-gamma-induced host defense. Genes Dev. 2007;21(15):1909-1920.

20. Tremblay AM, Giguère V. The NR3B subgroup: an ovERRview. Nucl Recept Signal. 2007;5:e009.

21. Charest-Marcotte A, Dufour CR, Wilson BJ, et al. The homeobox protein Prox 1 is a negative modulator of ERR $\{$ alpha\}/PGC-1 1 alpha\} bioenergetic functions. Genes Dev. 2010;24(6):537-542.

22. Deblois G, Giguère V. Nuclear receptor location analyses in mammalian genomes: from gene regulation to regulatory networks. Mol Endocrinol. 2008;22(9):1999-2011

23. Deblois G, Giguère V. Oestrogen-related receptors in breast cancer: control of cellular metabolism and beyond. Nat Rev Cancer. 2013;13(1):27-36.

24. Eichner LJ, Giguère V. Estrogen related receptors (ERRs): a new dawn in transcriptional control of mitochondrial gene networks. Mitochondrion. 2011;11(4):544-552.

25. Franceschini A, Szklarczyk D, Frankild S, et al. STRING v9.1: proteinprotein interaction networks, with increased coverage and integration. Nucleic Acids Res. 2013;41(Database issue):D808-D815.

26. Deberardinis RJ, Lum JJ, Hatzivassiliou G, Thompson CB. The biology of cancer: metabolic reprogramming fuels cell growth and proliferation. Cell Metab. 2008;7(1):11-20.

27. Jones RG, Thompson CB. Tumor suppressors and cell metabolism: a recipe for cancer growth. Genes Dev. 2009;23(5):537-548.

28. Galluzzi L, Kepp O, vander Heiden MG, Kroemer G. Metabolic targets for cancer therapy. Nat Rev Drug Discov. 2013;12(11):829-846.

29. Girnun GD. The diverse role of the PPAR $\gamma$ coactivator 1 family of transcriptional coactivators in cancer. Semin Cell Dev Biol. 2012;23(4):381-388.

30. Park S, Chang CY, Safi R, et al. ERR $\alpha$-Regulated lactate metabolism contributes to resistance to targeted therapies in breast cancer. Cell Rep. 2016;15(2):323-335.

31. Bianco S, Lanvin O, Tribollet V, Macari C, North S, Vanacker JM. Modulating estrogen receptor-related receptor-alpha activity inhibits cell proliferation. J Biol Chem. 2009;284(35):23286-23292.

32. Bernatchez G, Giroux V, Lassalle T, Carpentier AC, Rivard N, Carrier JC. ERR $\alpha$ metabolic nuclear receptor controls growth of colon cancer cells. Carcinogenesis. 2013;34(10):2253-2261.

33. Colombo SL, Palacios-Callender M, Frakich N, et al. Molecular basis for the differential use of glucose and glutamine in cell proliferation as revealed by synchronized HeLa cells. Proc Natl Acad Sci U S A. 2011;108(52): 21069-21074.
34. Bao Y, Mukai K, Hishiki T, et al. Energy management by enhanced glycolysis in G1-phase in human colon cancer cells in vitro and in vivo. Mol Cancer Res. 2013;11(9):973-985.

35. Willy PJ, Murray IR, Qian J, et al. Regulation of PPARgamma coactivator 1alpha (PGC-1alpha) signaling by an estrogen-related receptor alpha (ERRalpha) ligand. Proc Natl Acad Sci U S A. 2004;101(24): 8912-8917.

36. Chisamore MJ, Cunningham ME, Flores O, Wilkinson HA, Chen JD. Characterization of a novel small molecule subtype specific estrogenrelated receptor alpha antagonist in MCF-7 breast cancer cells. PLoS One. 2009;4(5):e5624.

37. Matsushima $\mathrm{H}$, Mori T, Ito $\mathrm{F}$, et al. Anti-tumor effect of estrogen-related receptor alpha knockdown on uterine endometrial cancer. Oncotarget. 2016;7(23):34131-34148.

38. Bergers G, Benjamin LE. Tumorigenesis and the angiogenic switch. Nat Rev Cancer. 2003;3(6):401-410.

39. Ao A, Wang H, Kamarajugadda S, Lu J. Involvement of estrogen-related receptors in transcriptional response to hypoxia and growth of solid tumors. Proc Natl Acad Sci U S A. 2008;105(22):7821-7826.

40. Gordan JD, Simon MC. Hypoxia-inducible factors: central regulators of the tumor phenotype. Curr Opin Genet Dev. 2007;17(1): 71-77.

41. Arany Z, Foo SY, Ma Y, et al. HIF-independent regulation of VEGF and angiogenesis by the transcriptional coactivator PGC-1alpha. Nature. 2008;451(7181):1008-1012.

42. Stein RA, Gaillard S, McDonnell DP. Estrogen-related receptor alpha induces the expression of vascular endothelial growth factor in breast cancer cells. J Steroid Biochem Mol Biol. 2009;114(1-2):106-112.

43. Semenza GL. Defining the role of hypoxia-inducible factor 1 in cancer biology and therapeutics. Oncogene. 2010;29(5):625-634.

44. Zhang LD, Chen L, Zhang M, et al. Downregulation of ERR $\alpha$ inhibits angiogenesis in human umbilical vein endothelial cells through regulating VEGF production and PI3K/Akt/STAT3 signaling pathway. Eur $J$ Pharmacol. 2015;769:167-176.

45. Chen Z, Yuhanna IS, Galcheva-Gargova Z, Karas RH, Mendelsohn ME, Shaul PW. Estrogen receptor alpha mediates the nongenomic activation of endothelial nitric oxide synthase by estrogen. J Clin Invest. 1999;103(3):401-406.

46. Sumi D, Ignarro LJ. Estrogen-related receptor alpha 1 up-regulates endothelial nitric oxide synthase expression. Proc Natl Acad Sci U SA. 2003;100(24):14451-14456.

47. Ying L, Hofseth LJ. An emerging role for endothelial nitric oxide synthase in chronic inflammation and cancer. Cancer Res. 2007;67(4):1407-1410.

48. Mori T, Sawada M, Kuroboshi H, et al. Estrogen-related receptor $\alpha$ expression and function are associated with vascular endothelial growth factor in human cervical cancer. Int J Gynecol Cancer. 2011;21(4): 609-615.

49. Zou C, Yu S, Xu Z, et al. ERR $\alpha$ augments HIF-1 signalling by directly interacting with HIF-1 $\alpha$ in normoxic and hypoxic prostate cancer cells. J Pathol. 2014;233(1):61-73.

50. Wang CW, Hsu WH, Tai CJ. Antimetastatic effects of cordycepin mediated by the inhibition of mitochondrial activity and estrogenrelated receptor $\alpha$ in human ovarian carcinoma cells. Oncotarget. 2017;8(2):3049-3058.

51. Jiang L, Xiao L, Sugiura $\mathrm{H}$, et al. Metabolic reprogramming during TGF $\beta 1$-induced epithelial-to-mesenchymal transition. Oncogene. 2015;34(30):3908-3916.

52. Aspuria PP, Lunt SY, Väremo L, et al. Succinate dehydrogenase inhibition leads to epithelial-mesenchymal transition and reprogrammed carbon metabolism. Cancer Metab. 2014;2:21.

53. Lam SS, Mak AS, Yam JW, Cheung AN, Ngan HY, Wong AS. Targeting estrogen-related receptor alpha inhibits epithelial-to-mesenchymal transition and stem cell properties of ovarian cancer cells. Mol Ther. 2014;22(4):743-751.

54. Zhao Y, Li Y, Lou G, et al. MiR-137 targets estrogen-related receptor alpha and impairs the proliferative and migratory capacity of breast cancer cells. PLoS One. 2012;7(6):e39102. 
55. Dwyer MA, Joseph JD, Wade HE, et al. WNT11 expression is induced by estrogen-related receptor alpha and beta-catenin and acts in an autocrine manner to increase cancer cell migration. Cancer Res. 2010;70(22):9298-9308.

56. Deblois G, Chahrour G, Perry MC, Sylvain-Drolet G, Muller WJ, Giguère V. Transcriptional control of the ERBB2 amplicon by ERRalpha and PGC-1beta promotes mammary gland tumorigenesis. Cancer Res. 2010;70(24):10277-10287.

57. Carracedo A, Cantley LC, Pandolfi PP. Cancer metabolism: fatty acid oxidation in the limelight. Nat Rev Cancer. 2013;13(4):227-232.

58. Nieman KM, Kenny HA, Penicka CV, et al. Adipocytes promote ovarian cancer metastasis and provide energy for rapid tumor growth. Nat Med. 2011;17(11):1498-1503.

59. Kim HM, Jung WH, Koo JS. Site-specific metabolic phenotypes in metastatic breast cancer. J Transl Med. 2014;12:354.

60. Deblois G, Smith HW, Tam IS, et al. ERR $\alpha$ mediates metabolic adaptations driving lapatinib resistance in breast cancer. Nat Commun. 2016;7:12156.

61. Zahid M, Beseler CL, Hall JB, Levan T, Cavalieri EL, Rogan EG. Unbalanced estrogen metabolism in ovarian cancer. Int J Cancer. 2014;134(10): 2414-2423.

62. Lowe KA, Chia VM, Taylor A, et al. An international assessment of ovarian cancer incidence and mortality. Gynecol Oncol. 2013;130(1): $107-114$

63. Kipps E, Tan DS, Kaye SB. Meeting the challenge of ascites in ovarian cancer: new avenues for therapy and research. Nat Rev Cancer. 2013;13(4):273-282.

64. Ayantunde AA, Parsons SL. Pattern and prognostic factors in patients with malignant ascites: a retrospective study. Ann Oncol. 2007;18(5):945-949.

65. Papadimitriou CA, Markaki S, Siapkaras J, et al. Hormonal therapy with letrozole for relapsed epithelial ovarian cancer. Long-term results of a phase II study. Oncology. 2004;66(2):112-117.

66. Williams C, Simera I, Bryant A, Platt J, Cochrane Gynaecological, Neuro-oncology and Orphan Cancer Group. Tamoxifen for relapse of ovarian cancer. Cochrane Database Syst Rev. 2010;60(abstr 782).
67. Johnston SD, Liu X, Zuo F, et al. Estrogen-related receptor alpha 1 functionally binds as a monomer to extended half-site sequences including ones contained within estrogen-response elements. Mol Endocrinol. 1997;11(3):342-352.

68. Vanacker JM, Pettersson K, Gustafsson JA, Laudet V. Transcriptional targets shared by estrogen receptor- related receptors (ERRs) and estrogen receptor (ER) alpha, but not by ERbeta. Embo J. 1999;18(15):4270-4279.

69. Kraus RJ, Ariazi EA, Farrell ML, Mertz JE. Estrogen-related receptor alpha 1 actively antagonizes estrogen receptor-regulated transcription in MCF-7 mammary cells. J Biol Chem. 2002;277(27):24826-24834.

70. Fujimoto J, Alam SM, Jahan I, Sato E, Sakaguchi H, Tamaya T. Clinical implication of estrogen-related receptor (ERR) expression in ovarian cancers. J Steroid Biochem Mol Biol. 2007;104(3-5):301-304.

71. Fujimoto J, Sato E. Clinical implication of estrogen-related receptor (ERR) expression in uterine endometrial cancers. J Steroid Biochem Mol Biol. 2009;116(1-2):71-75.

72. Ariazi EA, Clark GM, Mertz JE. Estrogen-related receptor alpha and estrogen-related receptor gamma associate with unfavorable and favorable biomarkers, respectively, in human breast cancer. Cancer Res. 2002;62(22):6510-6518.

73. Chen EI, Hewel J, Krueger JS, et al. Adaptation of energy metabolism in breast cancer brain metastases. Cancer Res. 2007;67(4):1472-1486.

74. Hanahan D, Weinberg RA. Hallmarks of cancer: the next generation. Cell. 2011;144(5):646-674.

75. Busch BB, Stevens WC, Martin R, et al. Identification of a selective inverse agonist for the orphan nuclear receptor estrogen-related receptor alpha. J Med Chem. 2004;47(23):5593-5596.

76. Sun P, Mao X, Gao M, et al. Novel endocrine therapeutic strategy in endometrial carcinoma targeting estrogen-related receptor $\alpha$ by XCT790 and siRNA. Cancer Manag Res. 2018;10:2521-2535.

77. Patch RJ, Searle LL, Kim AJ, et al. Identification of diaryl ether-based ligands for estrogen-related receptor $\alpha$ as potential antidiabetic agents. J Med Chem. 2011;54(3):788-808.

78. Zhang L, Liu P, Chen H, et al. Characterization of a selective inverse agonist for estrogen related receptor $\alpha$ as a potential agent for breast cancer. Eur J Pharmacol. 2016;789:439-448.
Cancer Management and Research

\section{Publish your work in this journal}

Cancer Management and Research is an international, peer-reviewed open access journal focusing on cancer research and the optimal use of preventative and integrated treatment interventions to achieve improved outcomes, enhanced survival and quality of life for the cancer patient. The manuscript management system is completely online and includes

\section{Dovepress}

a very quick and fair peer-review system, which is all easy to use. Visit http://www.dovepress.com/testimonials.php to read real quotes from published authors. 